\title{
DIFICULDADES DE APRENDIZAGEM NO ENSINO SUPERIOR:
} REFLEXÕES A PARTIR DA PERSPECTIVA PIAGETIANA

\section{Eliane Giachetto Saravali}

\section{RESUMO}

O texto apresenta uma breve revisão histórica do termo "dificuldades de aprendizagem" e as diferentes influências que este campo de estudo vem sofrendo. Discute-se a perspectiva construtivista do termo e as suas contribuições para a educação. As questões relacionadas à aprendizagem do aluno universitário, bem como a compreensão do raciocínio operatório formal e as dificuldades de aprendizagem no ensino superior também são abordadas no artigo.

\section{PALAVRAS-CHAVE}

Dificuldades de aprendizagem; Raciocínio operatório formal; Construtivismo

\section{LEARNING DISABILITIES IN HIGHER EDUCATION: REFLECTIONS FROM A PIAGETIAN PERSPECTIVE}

\section{ABSTRACT \\ The text presents a brief review of the history of the term "learning disabilities" and the different influences that this field of studies has passed through. The constructivist perspective of the term is discussed and its contribution to education. Questions related to learning and the university student, as well as understanding of formal operative thinking and the difficulties of learning in higher education are also addressed in the article.}

\section{KEYWORDS}

Learning disabilities; Formal operative thinking; Cconstructivism 
Atualmente, a sociedade assiste ao caos da escola pública que forma alunos com sérias lacunas nos seus conhecimentos e grandes dificuldades para a aprendizagem, fatos que acabam ficando bastante evidenciados quando esses alunos atingem o ensino superior.

Nesse sentido, o quadro que se apresenta é o seguinte: o aluno proveniente do ensino público e que chega à faculdade ${ }^{1}$ teve uma escolarização precária com todos os problemas que a caracterizam (professores mal formados e mal remunerados, salas de aula super lotadas, greves, péssimas condições de trabalho etc.) e vai iniciar a nova etapa de escolarização sem dominar conceitos e conteúdos básicos que o impedem de acompanhar as solicitações do meio universitário.

Pensando nessas questões e no contexto atual em que o campo de estudo sobre as dificuldades de aprendizagem vem se ampliando, o presente capítulo pretende apontar e refletir acerca de algumas questões que envolvem os problemas na aprendizagem dos estudantes universitários. O que pode caracterizar um aluno que vem fracassando no ensino superior do ponto de vista da aprendizagem? Quais as intervenções e ações que a universidade, principalmente os professores universitários devem realizar?

Em tempos de debates sobre a reforma universitária, é importante considerar que o verdadeiro ensino democrático é aquele que não somente garante o acesso, mas sobretudo a permanência do aluno, enfocando a formação integral e não somente o preparo profissional. Portanto, quando esse aluno chega à instituição superior e não consegue usufruir do ensino que ela e seus mestres promovem, acompanhar suas leituras e exercícios, desenvolver habilidades, aprender a acessar o conhecimento, a educação está longe de atingir seu ideal democrático.

Pretendemos, também, apontar as contribuições que o modelo de desenvolvimento e aprendizagem criados por Piaget trazem para o estudo do aluno

\footnotetext{
${ }^{1}$ Os termos faculdade e universidade serão usados aqui como sinônimos, pois nossa intenção não é analisar as diferenças institucionais, mas as questões relacionadas ao aluno universitário de forma geral, de qualquer tipo de instituição de ensino superior.
} 
universitário, enfocando o raciocínio do período operatório formal e o processo de equilibração majorante.

\section{DIFICULDADES DE APRENDIZAGEM: PANORAMA HISTÓRICO E CONCEITUAÇÃO}

Pesquisar e estudar a respeito das dificuldades de aprendizagem é um processo árduo e muitas vezes ambíguo e confuso. O termo traz consigo uma série de atributos que acabam ampliando o seu campo de definição. Assim, observa-se que a definição de dificuldades de aprendizagem pode variar de país para país e de autor para autor.

A idéia que nos parece essencial de ser colocada aqui e que constitui um consenso entre os diversos autores que abordam o problema, é que os indivíduos portadores de dificuldades de aprendizagem não têm sucesso na escola por diferentes razões, mas não por possuírem uma deficiência mental. Muitos daqueles que têm dificuldade de aprendizagem são erroneamente classificados como tendo baixa inteligência, insolência ou preguiça e são solicitados por adultos (professores e pais) geralmente ansiosos e preocupados com seu rendimento, o que por si só, pode gerar o agravamento do problema (SMITH e STRICK, 2001). Senf (apud Fonseca, 1995) afirma que a dificuldade de aprendizagem tem sido uma área obscura situada entre a normalidade e a defectologia. Nas escolas, é comum os professores encaminharem e/ ou sugerirem um "acompanhamento especial” para os problemas dos estudantes sem, contudo, procederem a uma avaliação e intervenção adequadas.

Buscando as origens do termo na história, é possível encontrar referências à questão das dificuldades de aprendizagem (DA) já em 1800. Segundo Cruz (1999), algumas fases caracterizam as pesquisas e estudos sobre o tema:

\section{- $\quad$ Fase da Fundação (1800 a 1930)}

Nesta fase há o predomínio da abordagem organicista para as DA. A medicina nos seus diferentes ramos (neurologia, oftalmologia, psiquiatria) compunha o leque de profissionais que mais se interessavam pela área. É compreensível portanto que ainda hoje, 


\section{ARTIGO \\ Área Temática: Estudos Piagetianos \& Psicologia Clínica e Educacional}

muitas vezes, tenhamos termos da área médica para definir as DA, tais como distúrbios, anormalidade, disfunção cerebral mínima, disgrafias, afasias, dislexias e outros, sempre associados a fatores orgânicos tais como problemas cerebrais, traumatismos e deficiência cerebral.

O que se observa como característica desse momento histórico é a busca da relação dos problemas de aprendizagem com pontos cerebrais comprometidos, por exemplo: problemas no processamento da linguagem indicariam algum tipo de mau funcionamento em determinada área do cérebro. Surge a idéia de lesão mínima ou de desenvolvimento insuficiente. Sobre este período Cruz (1999) afirma que:

... a história das dificuldades de aprendizagem encontra as suas heranças nos estudos neuropsicológicos de adultos que perderam a habilidade para falar, ler, escrever ou calcular depois de sofrerem uma lesão cerebral. Tais investigações e teorias foram posteriormente alargadas às crianças que falhavam no normal desenvolvimento das habilidades da linguagem ou da leitura (p.23).

- $\quad$ Fase da Transição (1930 a 1963)

Nesse momento, não se apresentam somente estudos e definições centrados numa perspectiva orgânica e biológica, mas também há referências a fatores ligados a aspectos psicológicos, sobretudo em razão da participação e interesse de profissionais do campo da Psicologia e Educação. Nesse sentido, observa-se também a proliferação de testes e programas de recuperação. Destacamos alguns autores e seus trabalhos:

Strauss e Werner (Strauss et al, 1973)- pioneiros em explicar os processos gerais de aprendizagem, comparavam crianças com lesões cerebrais e crianças com deficiência mental (sem lesões). Strauss inclusive diferencia 2 tipos de lesões - endógenas (deficiência mental em razão de características herdadas e familiares) e exógenas (decorrentes de déficits neurológicos ou lesões cerebrais provocadas por problemas pré, peri e pós natais). As contribuições destes dois autores são fundamentais pois com base em suas pesquisas, já se apontava para a necessidade de uma intervenção educativa especial nos casos de lesões. Cumpre destacar também as orientações educativas que eles apresentavam na recuperação dos problemas de aprendizagem apresentados por estas crianças: 1) necessidade em se abordar os diferentes modos que cada criança utiliza para 
resolver as tarefas que lhe são solicitadas; 2) importância em se relacionar os procedimentos educativos com as facilidades e dificuldades apresentadas pela criança e 3) necessidade de não se ressaltar as áreas fracas de aprendizagem, mas sim fortalecer os processos mais fortes.

Cruickshank (Cruickshank e Johnson, 1975) - apresenta a idéia de lesão cerebral mínima não diagnosticada num exame neurológico, mas observada por comportamentos inadequados no momento da aprendizagem, tais como dificuldades de formação de conceitos.

Kephart - (1990) faz uma associação entre as habilidades sensório-motoras e as habilidades visuo-perceptivas. Defende que as funções intelectuais superiores (simbolização, conceitualização) dependem de aquisições perceptivo-motoras básicas. Nesse sentido, a sensação e a percepção são indissociáveis da motricidade.

Frostig (FROSTIG e MASLOW, 1973) - enfatizou a percepção visual, cuja anormalidade afetaria as funções cognitivas. Procurou relacionar partes do cérebro que não funcionam bem com problemas na percepção, como exemplo: reconhecimento de formas, distâncias, cores. Elaborou juntamente com Maslow, LeFever e Whinttlesey o primeiro teste de percepção visual e criou também um programa de treinamento nesta área. A percepção visual é definida pela autora como a habilidade de reconhecer e discriminar estímulos visuais e interpretar tais estímulos por associação com experiências prévias. O teste compreendia cinco áreas: 1) coordenação visuo-motora ou coordenação olho-mão; 2) discriminação figura-fundo; 3) constância da forma ou constância perceptiva; 4) posição no espaço e 5) relações espaciais. Sobre estas áreas explicam:

Percepção da posição no espaço é considerada como essencial para leitura por muitos educadores porque sem ela a criança não pode diferenciar as letras, como por exemplo b e d. Percepção da relação espacial é essencial para a ortografia; a criança deve perceber a seqüência de letras e ser capaz de colocá-las na ordem certa. Constância perceptiva é importante para a habilidade de discriminar detalhes minuciosos, como exemplo, um $\mathrm{r}$ de um n, ou um a de um d. Coordenação visuomotora não é uma habilidade de percepção visual, mas é importante para realizar atividades como apagar, escrever e copiar, necessárias para a escola (1973, p.177). 


\section{ARTIGO Área Temática: Estudos Piagetianos \& Psicologia Clínica e Educacional}

Com relação à discriminação figura-fundo, os autores apontam que o treinamento nesta habilidade mostra que os alunos melhoram em suas capacidades de mudar a atenção apropriadamente, manter a concentração em estímulos relevantes e ignorar estímulos irrelevantes e também na capacidade de examinar minuciosamente um dado e de organização do próprio comportamento.

Myklebust (JOHNSON e MYKLEBUST, 1987) - interessou-se mais pelas desordens nos processos auditivos e da linguagem. Quantificou as DA comparando o potencial expectativo dos alunos e o seu nível de realização atual, afirmava que as DA “representam uma discrepância entre a capacidade e a realização, entre o potencial para a aprendizagem e o nível de aprendizagem atingido” (p.22). Procurou diferenciar uma criança com DA de uma criança deficiente mental pelo quociente de aprendizagem (QA). O cálculo do QA é feito comparando-se a idade mental com a capacidade de realizar tarefas próprias deste período da vida no qual a criança se encontra. Desta forma, este quociente indica o grau de aprendizagem atingido em relação ao potencial intelectual para a aprendizagem.

Quocientes de aprendizagem podem ser calculados para vários tipos de realização verbal e não-verbal, incluindo leitura, escrita, aritmética, percepção, visual e auditiva e facilidade com a palavra escrita (1987, p.23).

> Orton (apud FONSECA, 1995) - procurou identificar a relação entre atrasos e dificuldades na aprendizagem da leitura com a lentidão na aquisição ou a disfunção da dominância hemisférica, que implica em problemas com a lateralização no plano motor. Para ele, é necessário estabelecer primeiramente esta dominância e lateralização no plano motor a fim de evitar inversões, omissões, repetições durante a leitura. Sem ter adquirido uma dominância hemisférica, podemos experimentar uma grande confusão, e, portanto, dificuldades na aprendizagem da leitura. Para Orton, as inversões ocorrem porque as palavras são armazenadas no hemisfério não dominante e o indivíduo pode trocar b com d, u com n, por exemplo.

Kirk (1991) - Elaborou um dos testes mais famosos na história das DA o ITPA - Illinois Test of Psycholinguistic Abilities que avalia as possibilidades de comunicação do sujeito. Este teste trouxe grandes contribuições para o desenvolvimento de programas individualizados de educação, uma vez que discrimina, nos sujeitos, as aquisições fortes 
das fracas. O ITPA é composto por dez subtestes envolvendo as áreas de recepção auditiva e visual - capacidade de captar significados de palavras e símbolos visuais; associação auditiva e visual - capacidade de relacionar conceitos apresentados auditiva e visualmente; expressão de conceitos em termos verbais e manuais; memória seqüencial, auditiva e visual e avaliação gramatical.

- $\quad$ Fase da Integração (1963 a 1980)

Iniciou-se em 1963 quando Samuel Kirk apresentou o termo dificuldade de aprendizagem na "Conference on Exploration into Problems of the Perceptually Handicapped Child”, caracterizando-o da seguinte forma:

... um atraso, desordem ou imaturidade num ou mais processos da linguagem falada, da leitura, da ortografia, da caligrafia ou da aritmética, resultantes de uma possível disfunção cerebral e/ou distúrbios do comportamento e não dependentes de uma deficiência mental, de uma privação sensorial, de uma privação cultural ou de um conjunto de fatores pedagógicos (CRUZ, 1999, p.30).

Assim, nesse momento, observou-se o reconhecimento desse campo como área específica com estudos e atividades próprias bem como o aumento considerável de pesquisas e definições, programas educativos e publicações voltadas para a temática das dificuldades de aprendizagem. Este interesse sobre as DA levou à fundação e surgimento de associações e organizações tematizadas, houve a ampliação de programas educativos bem como a disponibilização de fundos governamentais e o aumento do interesse geral inclusive por parte de pais e profissionais de diversas áreas (professores, médicos, psicólogos). Nessa fase destacamos os seguintes autores:

Ross (1979) - caracterizou os sujeitos portadores de DA como tendo problemas naquilo que denominou de atenção seletiva - capacidade de decodificar e filtrar os elementos relevantes, desconsiderando informações desnecessárias. Nesse sentido, os problemas com a aprendizagem são causados em razão de uma dificuldade nas funções de rememorização e de reorganização da informação em razão de uma atenção seletiva menos controlada e menos intencional. 
$>$ Vellutino (1977) - apresenta a teoria do Déficit Verbal segundo a qual as dificuldades na leitura são causadas por problemas fonológicos, semânticos e sintáticos associados a problemas de codificação, sínteses, retomada da informação, memória de curto termo, ocasionando lentidão na identificação e uso das palavras. Estes problemas se caracterizam pela demora na decodificação das palavras que prejudica os maus leitores, pois estando concentrados na tarefa de decodificar as palavras, acabam tendo dificuldade em recordar a informação contida nas frases lidas previamente.

Bateman (Haring e Bateman, 1977) - não se baseia tanto no enfoque de déficits psicológicos, mas centra-se nas condições externas oferecidas ao educando, como por exemplo: materiais didáticos adequados, programação pedagógica entre outros.

$>$ Torgensen (apud Fonseca, 1995) - elabora a abordagem do Educando Passivo. Fundamenta-se na Teoria Cognitiva do Processamento da Informação e na Psicologia Evolutiva e Diferencial. O enfoque está baseado na atividade do educando, ou seja, na utilização de estratégias adequadas para o processamento da informação. Segundo este autor, o aluno sem DA adota estratégias adequadas na realização de suas tarefas, tendo uma participação ativa no seu processo de aprendizagem. O indivíduo com DA acaba não assumindo um papel ativo na sua aprendizagem, apresentando déficits na execução das tarefas.

Adelman (apud Cruz, 1999) - Propõe o Modelo Interacional, no qual se apresenta a idéia de que a origem das DA não estaria somente no sujeito, seria o resultado da interação entre as áreas fortes e fracas deste, juntamente com os aspectos ligados à escolarização. $\mathrm{O}$ mesmo autor propõe posteriormente uma Perspectiva Transacional das DA que pode ser explicada pela existência de três tipos de problemas no aprendizado. O tipo I caracterizase pelos problemas gerados exclusivamente por inadequações no meio em que o sujeito está inserido, como por exemplo, o programa escolar. No tipo II estão os problemas resultantes da interação entre indivíduo e meio e no tipo III problemas causados exclusivamente por características do indivíduo, como por exemplo: desordens no sistema nervoso central. 
- $\quad$ Fase Contemporânea (1980 até a atualidade)

Nesse período, segundo Cruz (1999), há um estreitamento entre os diversos conceitos do campo e a tentativa de recorte nas definições. Há uma grande contribuição de diferentes teorias e investigadores. O autor apresenta a existência de três grandes influências:

1) Influência da Análise Aplicada do Comportamento

A ênfase nesta abordagem está nos problemas que o meio apresenta. Dessa forma, uma dificuldade de aprendizagem é o resultado de um comportamento ou resposta inadequada ao estímulo apresentado que pode ser alterada mudando-se este estímulo, ou seja, fazendo-se as alterações necessárias no meio.

2) Influência da teoria do Processamento da Informação

Sob esta perspectiva nota-se que a preocupação está na atividade cognitiva do sujeito. Rebelo e Casas (apud Cruz, 1999) afirmam que as DA correspondem a deficiências nas funções de processamento psicológico acarretando em problemas para adquirir e integrar as novas informações que são solicitadas pela escola.

\section{3) Influência da Perspectiva Neuropsicológica}

Nesta perspectiva, nota-se a ênfase no funcionamento cerebral. Dessa forma, áreas com lesões, mau funcionamento, desequilíbrio químico são causas de aprendizagens desajustadas.

Apesar da origem desta perspectiva estar em fases anteriores, na atualidade considerase de extrema relevância tais estudos. Os resultados dessas pesquisas têm apontado para uma intervenção com os portadores de DA para a recuperação das áreas com problemas ou na compensação das áreas fortes do indivíduo.

Fonseca (1995) apresenta um quadro, que gostaríamos de reproduzir sintetizando as informações anteriores, mostrando as diferentes influências que as pesquisas sobre DA sofreram, como pudemos ver na breve revisão histórica apresentada aqui: 


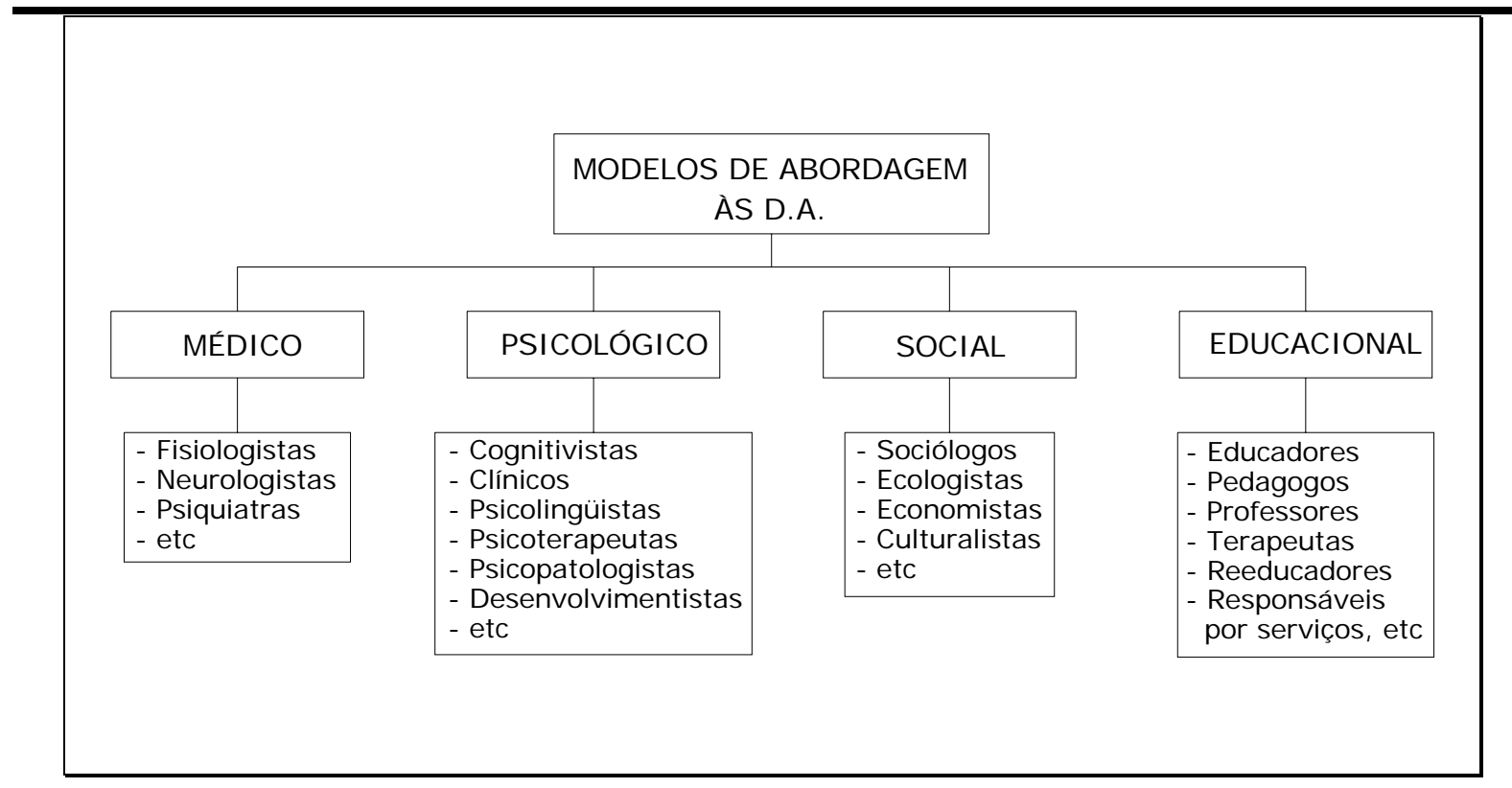

Figura 1: Modelo de abordagem às DA, conforme Fonseca (1995, p.51).

Essa gama de influências denota em diferentes perspectivas e grandes dificuldades para a definição e delimitação deste campo:

Em resumo, as teorias das dificuldades de aprendizagem são controversas, conceitualmente confusas e raramente apresentam dados de aplicação educacional imediata. Mesmo com uma grande panorâmica e com um grande potencial de investigação, as teorias das DA continuam a ser muito complexas e muito pouco consistentes (FONSECA, 1995, p.57-58).

Toda essa revisão histórica nos ajuda a compreender os motivos que tornam o campo das dificuldades de aprendizagem tão confuso. É possível notar que há um grupo heterogêneo de sintomas que caracterizam as DA. É justamente a concepção de causa multifatorial que reveste de múltiplos significados a busca por uma definição.

Sisto (2001) demarca o que seria e o que não seria caracterizado como DA em concordância com a definição de 1988 do National Joint Committee on Learning Disabilities (NJCLD), uma das mais aceitas na atualidade: 
1) Problemas nas condutas auto-reguladoras da percepção ou interação social, como por exemplo, déficits de atenção e hiperatividade ${ }^{2}$, (apesar de outros autores discordarem) não constituem uma DA, embora possam ser sintomas de pessoas com DA; ${ }^{3}$

2) DA não se caracterizam por problemas como deficiências sensoriais, retardo mental, transtorno emocional, condições culturais, ensino inadequado ou insuficiente. Entretanto, pode haver co-ocorrência destes problemas com as DA e "também não se discute que essas condições produzem dificuldades de aprendizagem” (Sisto, 2001, p. 32);

3) Dificuldades de aprendizagem correspondem a dificuldades intrínsecas ao indivíduo supostamente devido a uma disfunção do sistema nervoso central e estão baseadas em estudos neuropsicológicos e genéticos;

4) Em qualquer idade é possível uma pessoa manifestar DA, indicando que esse problema pode ser um desafio vitalício.

A maioria das definições concorda que alunos com incapacidade de aprendizagem têm pelo menos inteligência média, mas têm significativos problemas acadêmicos e desempenho significativamente mais baixo do que seria esperado (WOOLFOLK, 2000, p. 132).

Assim, poder-se-ia definir que o termo dificuldades de aprendizagem engloba um grupo heterogêneo de transtornos, manifestando-se por meio de atrasos ou dificuldades em leitura, escrita, soletração e cálculo, em pessoas com inteligência potencialmente normal ou superior e sem deficiências visuais, auditivas, motoras, ou desvantagens culturais. Geralmente não ocorre em todas essas áreas de uma só vez e pode estar relacionada a problemas de comunicação, atenção, memória, raciocínio, coordenação, adaptação social e problemas emocionais (SISTO, 2001). O indivíduo com DA não possui rebaixamento de QI indicando

\footnotetext{
${ }^{2}$ Smith e Strick (2001) definem o Transtorno de Déficit de Atenção com ou sem Hiperatividade (TDAH) como uma dificuldade em manter a atenção, a concentração e os impulsos. Ressaltam que é preciso um diagnóstico rigoroso a fim de não se rotular alguém que não tenha TDAH. Há vários sintomas que precisam ser constantes e ocorrerem sempre para se caracterizar um caso de TDAH, como por exemplo: freqüentemente deixar de prestar atenção a detalhes, dificuldade em manter a atenção em tarefas, dificuldade em seguir instruções, remexer-se constantemente na cadeira retorcendo pés e mãos, dificuldade em esperar a própria vez, falar excessivamente, entre outros.

${ }^{3}$ É importante ressaltar que diferentemente do que propõe o NJCLD, o ICLD The Interagency Committee on Learning Disabilities composto por 13 agências federais norte-americanas, em 1987, defendeu que as inabilidades sociais constituem dificuldade de aprendizagem específica. Em sua definição, o ICLD propõe que as DA sejam classificadas considerando-se 5 áreas: a) neurologia da aprendizagem e memória; b) dificuldades
} 
aquilo que muitos autores chamam de conduta discrepante acentuada entre o potencial para a aprendizagem e o desempenho acadêmico.

Conforme Sisto (2001), as co-ocorrências precisam ser investigadas e merecem especial atenção daqueles que lidam com os indivíduos com dificuldades de aprendizagem. Smith e Strick (2001) apontam que:

... o termo dificuldades de aprendizagem refere-se não a um único distúrbio, mas a uma ampla gama de problemas que podem afetar qualquer área do desempenho acadêmico. Raramente, elas podem ser atribuídas a uma única causa: muitos aspectos diferentes podem prejudicar o funcionamento cerebral, e os problemas psicológicos dessas crianças freqüentemente são complicados, até certo ponto, por seus ambientes doméstico e escolar (grifo nosso, p.15).

Para estas autoras, embora supostamente as dificuldades de aprendizagem tenham uma base biológica, o ambiente do aluno, familiar e escolar, determinam a gravidade do impacto da dificuldade.

É nesse ponto que gostaríamos de concordar e assumir a posição de Fonseca (1995) quando este advoga que para definirmos ou mesmo pensarmos em dificuldades de aprendizagem devemos adotar uma atitude interacional e dialética, ou seja, procurar integrar os déficits no indivíduo, na escola, família e outros pois “... as condições internas (neurobiológicas) e as condições externas (sócio-culturais) desempenham funções dialéticas (psicoemocionais) que estão em jogo na aprendizagem humana.” (p.12). Cruz (1999) chega mesmo a dizer que dependendo da orientação que se segue, cada autor tem uma tendência a se inclinar para um certo aspecto na etiologia das DA, seja ele fisiológico, sociocultural ou institucional.

Dessa forma, é importante considerar que ambientes escolares e domésticos podem afetar o desenvolvimento e o potencial para a aprendizagem. Por exemplo: crianças que foram privadas de um ambiente estimulante nos primeiros anos: nutrição, higiene, saúde e sono, 


\section{ARTIGO \\ Área Temática: Estudos Piagetianos \& Psicologia Clínica e Educacional}

podem desenvolver problemas que interferem no seu aprendizado. (SMITH e STRICK, 2001).

O ambiente escolar também pode ser ou não estimulante, oferecendo ou não as oportunidades apropriadas de aprendizagem, não bastando somente ser capaz de aprender.

Se o sistema educacional não oferece isso, os alunos talvez nunca possam desenvolver sua faixa plena de capacidades, tonando-se efetivamente 'deficientes', embora nada haja de fisicamente errado com eles [...] A verdade é que muitos alunos fracos são vítimas da incapacidade de suas escolas para ajustarem-se às diferenças individuais e culturais (SMITH e STRICK., 2001, p.33-34).

\section{A PERSPECTIVA CONSTRUTIVISTA DAS DIFICULDADES DE APRENDIZAGEM}

Sob o enfoque piagetiano da construção do conhecimento, gostaríamos de abordar o que denominamos de perspectiva construtivista das dificuldades de aprendizagem. Optamos por abordar essa perspectiva pois acreditamos que é bastante coerente com o quadro educacional atual e que, muitos dos alunos que estão à margem do sistema de ensino, excluídos dentro da própria sala de aula, rotulados como incapazes, ou mesmo, como portadores de dificuldades de aprendizagem, se enquadram no que os autores desta linha defendem.

Assumindo a perspectiva interacionista-construtivista de Jean Piaget (1896-1980) os adeptos desta visão identificam os problemas de aprendizagem como resultantes de falhas no processo de relação do sujeito com o meio, pressuposto básico do construtivismo. Vejamos primeiramente um pouco a respeito desta posição epistemológica assumida na teoria piagetiana.

Piaget teve como objetivo em toda a sua extensa obra responder às perguntas: Como atingimos o conhecimento? Como evoluímos de um patamar menos avançado de conhecimento para outro mais avançado?

Suas inúmeras pesquisas e publicações retratam o ponto de vista filosófico do postulado da construção, ou seja, adquirimos o conhecimento ou avançamos no processo de conhecer por meio de uma construção lenta e gradual. Tal construção ocorre desde o 


\section{ARTIGO Área Temática: Estudos Piagetianos \& Psicologia Clínica e Educacional}

nascimento e é fruto da interação indissociável entre o sujeito e o meio (físico e social) que o rodeiam.

Desta forma, o indivíduo age sobre o meio e o transforma assim como o compreende e o faz existir somente por meio desta ação. O papel do sujeito, que na concepção construtivista é ator principal do processo pois necessita agir para conhecer, está diretamente ligado às trocas que pode realizar com o meio. Portanto, quanto mais ricas e oportunas forem essas trocas, melhores condições de desenvolvimento existirão.

Piaget não realizou pesquisas na área das dificuldades de aprendizagem, no entanto, é possível observar que sua teoria é extremamente atual para os estudos neste campo.

Muitos seguidores da obra piagetiana vêm dedicando-se ao tema das dificuldades de aprendizagem sob o enfoque construtivista. A pergunta central que norteia o trabalho desses pesquisadores é “o que ocorre com as crianças que não atuam sobre o meio, por serem impedidas, ou atuam pouco?” (DOLLE e BELLANO, 1996, p.9). Dessa forma, sob essa perspectiva, os indivíduos que são incapazes de aprender, de conhecer, apresentam uma deficiência em um dos elementos ou em um dos momentos que formam o processo cognitivo, o qual encontra sua explicação na construção endógena das estruturas mentais em relação com a organização do real $^{4}$, a capacidade de representação e a linguagem. Para RamozziChiarottino (1994) as crianças que não aprendem sem que se saiba o porquê, não construíram ou construíram insuficientemente o real:

Depois de vários anos de observação do comportamento da criança em situação natural, chegamos à conclusão de que os distúrbios de aprendizagem são determinados por deficiências no aspecto endógeno do processo da cognição e de que a natureza de tais deficiências depende do meio no qual a criança vive e de suas possibilidades de ação neste meio, ou seja, depende das trocas do organismo com o meio, num período crítico de zero a sete anos (p.83).

\footnotetext{
${ }^{4}$ Real corresponde ao "mundo dos objetos e dos acontecimentos estruturados pela criança graças à aplicação de seus esquemas de ação. É por intermédio desses esquemas que a criança entende as propriedades dos objetos, as regularidades da Natureza e o alcance ou os limites de suas ações” (RAMOZZI-CHIAROTTINO, 1994, p.86).
} 


\section{ARTIGO \\ Área Temática: Estudos Piagetianos \& Psicologia Clínica e Educacional}

Assim para esta autora há uma causa orgânica para as DA parcialmente determinada pelo ambiente e possível de remediação. As pesquisas bastante interessantes e difundidas concentram-se mais no estudo das crianças que não têm sucesso na escola (Brenelli, 1996; Zaia, 1996), constituindo-se o campo de pesquisa com adultos bastante frutífero e potencial.

Segundo o enfoque construtivista, quando o aluno fracassa na escola, e não há déficits orgânicos, sensoriais e nem desordens psíquicas, há problemas na sua relação com o meio físico e social, ou seja, esse aluno não aprende porque suas possibilidades de ação sobre o meio e de conseqüente organização e reflexão dessa ação são prejudicadas. Portanto, para as dificuldades de aprendizagem, haveria não somente explicações orgânicas e intrínsecas ao sujeito (que deixam sobre o aluno uma carga de responsabilidade muito grande pelo fracasso), mas haveria também explicações de ordem interacional que podem e devem ser remediadas mediante uma intervenção e uma solicitação do meio ${ }^{5}$ adequada que auxilie o aluno a se desenvolver.

Dessa forma, aqueles que lidam com as situações de aprendizagem, principalmente os professores, necessitam estar atentos ao que está ocorrendo com os alunos. É preciso sim investigar porque os estudantes não aprendem, mas, sobretudo, quais são os meios que a escola pode se valer para minimizar as condições de fracasso que são impostas a esses alunos.

Diante dessas considerações, julgamos oportuno avaliar como estariam estas questões em relação ao aluno do ensino superior, tendo em vista sobretudo o contexto atual no qual muito se discute a respeito da qualidade da formação que esse aluno apresenta ao ingressar no ensino superior. Primeiramente, vejamos um pouco sobre as características do processo de aprendizagem do aluno adulto.

\footnotetext{
${ }^{5}$ O termo solicitação do meio será utilizado aqui no sentido abordado por Mantovani de Assis (1976) e refere-se à ação do professor que solicita continuamente o raciocínio do aluno, que organiza o ambiente e os materiais em função das necessidades de aprendizagem discentes, enfim o papel do educador enquanto desafiador e desequilibrador do processo de construção de conhecimentos pelos alunos.
} 


\section{A APRENDIZAGEM DO ADULTO}

Ao longo do nosso desenvolvimento nos deparamos com as inúmeras imposições e solicitações do meio físico e social e num processo de ação contínua nos desequilibramos e reequilibramos novamente, em busca de uma maior compreensão da realidade. Isso ocorre desde o nascimento e, segundo Piaget, vivemos diferentes momentos que caracterizam diferentes formas de compreender as informações com as quais nos deparamos. Essas formas se integram umas nas outras, modificando-se mutuamente e ampliando a capacidade de adaptação, o que torna o processo dinâmico.

Assim, num primeiro momento o bebê assimila o mundo por meio de suas ações (período sensório-motor), num segundo momento a criança "reapresenta" estas ações no plano do pensamento (período pré-operatório) e num terceiro momento, por volta dos 7, 8 anos, aproximadamente, a criança torna-se capaz de operar pois possui a reversibilidade do pensamento e lida com operações de classes, relações e números, ainda que presa à situação presente e concreta (período operatório concreto).

Segundo o referencial teórico piagetiano sobre o desenvolvimento humano, o estudante universitário estaria no período designado por operatório formal que inicia-se aproximadamente aos 11, 12 anos. De acordo com Piaget, o raciocínio do período formal apresenta indução experimental, verificação sistemática e a lógica das proposições:

O adolescente, ao contrário, superpõe a lógica das proposições à das classes e das relações, e assim desenvolve, pouco a pouco (atingindo seu patamar de equilíbrio por volta de 14-15 anos), um mecanismo formal fundamentado simultaneamente nas estruturas do reticulado e do grupo das 4 transformações; estas lhe permitirão reunir, num mesmo todo, além do raciocínio hipotético-dedutivo e da prova experimental baseada na variação de um único fator (desde que as outras coisas permaneçam iguais), certo número de esquemas operatórios que utilizará continuamente em seu pensamento experimental, bem como lógico-matemático. (INHELDER e PIAGET, 1976, p. 249-250).

Apesar do período formal ser o último do desenvolvimento, observa-se que há ainda muita construção a ser feita pelo adulto, pois as conquistas do novo raciocínio que 


\section{ARTIGO \\ Área Temática: Estudos Piagetianos \& Psicologia Clínica e Educacional}

teoricamente iniciam-se na adolescência, perdurarão por todo o restante do desenvolvimento, dando o caráter de continuidade para a evolução.

Assim, os adultos são seres em desenvolvimento tanto para aspectos cognitivos, como sociais, afetivos e físicos. Não se pode pensar que o pensamento do adulto está acabado pois é justamente a abstração do período formal que direciona esse pensamento para novas e sucessivas equilibrações, ampliando a abertura de possibilidades de interpretação, regulação e associação:

Este plano constitui, pela sua abertura aos possíveis, o ponto de partida de uma nova evolução, a da sociogenese ou desenvolvimento histórico dos conhecimentos, que se vai traduzir, por sua vez, na elaboração de formas de pensamento cada vez mais abstratas. O pensamento operatório formal surge, desde logo, como condição necessária, embora não suficiente, para a elaboração dessas novas formas de pensamento e para a assimilação dos conhecimentos que estas permitem elaborar. Por outras palavras, para assimilar os conhecimentos científicos elaborados no decurso da sociogenese, é necessário dispor das estruturas próprias do pensamento operatório formal. (LEGENDRE, 1998, p.183).

Para os adultos o meio não apresenta tantas novidades como para um bebê que inicia sua interação com o ambiente, todavia no seu processo de desenvolvimento há uma transformação conceitual daquilo que ele já construiu que se refere a uma transformação da experiência vivida. Assim, suas inúmeras experiências anteriores formam sistemas ou modelos pelos quais ele vai interpretar a realidade, portanto uma nova informação irá sempre ser observada pelo filtro desses saberes já construídos anteriormente e/ou servirá para reestruturá-los mediante um processo de equilibração.

É nesse sentido que podemos dizer que no caso dos adultos que já atingiram o pensamento formal, importa considerar um pouco mais a aprendizagem que o desenvolvimento, pois apesar da primeira estar subordinada ao segundo, é a integração de novas informações nos conhecimentos já construídos que imporá uma reestruturação mais ou menos profunda destes conhecimentos. É claro que não podemos esquecer que são as estruturas intelectuais que permitem a compreensão ou não do novo dado que passa a ser inserido num sistema de significação. Piaget defendeu a articulação entre forma e conteúdo mostrando que ao longo do desenvolvimento construímos as estruturas intelectuais (forma) que nos permitem apreender a realidade e que estas estão relacionadas com a bagagem que o sujeito foi acumulando (conteúdo). 
Essa relação dialética entre forma e conteúdo nos permite compreender que os conhecimentos anteriores não são redutíveis aos instrumentos de raciocínio de que dispõe o adulto para estruturar a informação. Eles estão, igualmente, relacionados com a bagagem de conhecimentos e de experiências que o sujeito acumulou em relação a diversos campos ou domínios do saber.

Considerando estes aspectos iniciais sobre o desenvolvimento dos adultos e as questões relacionadas às diferentes perspectivas das dificuldades de aprendizagem, apontadas anteriormente, que reflexões podemos fazer a respeito do aluno do ensino superior? Passaremos a abordar algumas implicações educacionais no contexto universitário.

\section{IMPLICAÇÕES EDUCACIONAIS}

Muitos professores universitários estão experimentando situações inusitadas em suas salas de aula. Ao proporem atividades inerentes aos seus programas de ensino, estes mestres percebem que seus alunos trazem lacunas sérias no seu processo de aprendizagem características dos níveis mais básicos de ensino. Somente para citar algumas, consideremos os problemas com a leitura e escrita, tais como dificuldades na elaboração e interpretação de textos simples, dificuldades em ordenar idéias e refletir, dificuldade em produzir opinião e argumentar, problemas ortográficos, entre outros. E o que dizer então do desempenho dos alunos em disciplinas como cálculo e física?

Gostaríamos de abordar vários aspectos, o primeiro deles refere-se aos motivos pelos quais os alunos das IES têm apresentado desempenho tão aquém do esperado. Seriam estes estudantes portadores de dificuldades de aprendizagem no sentido mais usualmente aceito e definido pelo NJCLD conforme apontamos anteriormente? Será que misteriosas desordens intrínsecas estariam causando uma epidemia nos estudantes universitários? Ou, em contrapartida, seriam esses alunos frutos de um ensino deficitário desde a educação infantil, que não solicita seus processos de ação e equilibração e portanto não favorece a aprendizagem e o desenvolvimento, como defende uma abordagem construtivista das dificuldades de aprendizagem? Soma-se nesses casos, que este aluno também, muitas vezes, é 


\section{ARTIGO Área Temática: Estudos Piagetianos \& Psicologia Clínica e Educacional}

fruto de todo um ambiente cultural pouco solicitador e que hábitos como leitura, reflexão, debates são bastante raros.

É claro que não estamos negando que possam haver e que realmente haja casos de dificuldades de aprendizagem no sentido restrito do termo, que por uma série de razões não foram diagnosticados durante o percurso escolar desse aluno e que no ensino superior tornamse mais gritantes. São casos mais raros pois, no nosso entendimento, esse aluno dificilmente chega a essa etapa de escolarização, desistindo ou sendo forçado a desistir da escola anteriormente. Os alunos que constituem estes casos raros que alcançam o ensino superior, normalmente possuem condições financeiras e o esclarecimento familiar favorável, o que oferece a oportunidade de ajuda e compreensão ao que está ocorrendo com o estudante.

E os outros casos? São, a nosso ver, a maioria.

Muitas pesquisas realizadas na etapa do ensino fundamental nos mostram que crianças já bastantes adiantadas nos seus processos de escolarização, ainda não construíram os instrumentos intelectuais necessários à compreensão dos conteúdos abordados pela escola. Dentre estes instrumentos podemos citar as estruturas do período operatório concreto que não se consolidaram ainda e das quais os estudantes necessitam para estabelecerem relações, fazerem operações envolvendo classes etc. enfim responderem às exigências da escola.

\footnotetext{
Muitas destas crianças permanecem pré-operatórias ou iniciam a transição para o período operatório concreto apesar da idade e de freqüentarem classes mais adiantadas do ensino fundamental. Assim, em função da falta das operações, podem vir a apresentar problemas para aprender, cujos indicadores seriam as insuficiências em suas produções escolares (Zaia, 1996, p.34).
}

Nesse sentido, podemos pensar: se lá no início da escolarização estão ocorrendo atrasos, quem nos garante que esses adultos que conseguem cursar a faculdade já estão de posse dos mecanismos cognitivos característicos do pensamento formal? Ora, se o meio vem sendo desfavorável em todos os sentidos, sobretudo no processo de escolarização desse aluno, é bem provável que ao chegar no ensino superior ele ainda esteja construindo esquemas e estruturas cognitivas que deveriam ter sido consolidadas durante a adolescência. Dessa forma, o aluno teria sido confrontado, quase que exclusivamente, com conteúdos ou problemas que favorecem a utilização de esquemas operatórios concretos e não formais. Piaget afirmava que ao conquistar o período formal o adolescente passa a refletir sobre seu pensamento e construir 
teorias, aspectos esses indispensáveis para a assimilação de ideologias da sociedade. (INHELDER e PIAGET, 1976). Não seria exatamente sobre essa capacidade de reflexão dos universitários, ou ausência dela, que muitos professores têm se queixado?

Duas ações nos parecem importantes: a primeira refere-se aos casos em que as dificuldades de aprendizagem são diagnosticadas e, muitas vezes, somente são possíveis de serem minimizadas e não remediadas. Nesses casos, é necessário um certo tipo de acompanhamento e uma forma diferente de avaliação do aluno. Podemos citar como exemplo, o vestibular específico para disléxicos adotados pela FUVEST em $2003^{6}$ ou mesmo escolas de nível médio que procuram diversificar a aula e os procedimentos avaliativos a fim de garantir que alunos com problemas desse tipo possam acompanhar e aprender, segundo suas próprias características e capacidades. Nesse sentido, destacamos também que a Psicopedagogia que vem se constituindo como campo de saber consolidado relacionado à aprendizagem, pode e deve direcionar suas ações e pesquisas para o ensino superior. Assim, para esses alunos, o acompanhamento psicopedagógico seria bastante importante no intuito de auxiliá-los a percorrerem da melhor forma os caminhos que se abrem. Esse acompanhamento psicopedagógico que deve ocorrer num nível clínico, não pode prescindir de uma ação psicopedagógica institucional que auxilie os professores a compreenderem também estas questões e a tornarem-se cúmplices e atuantes no processo de aprendizagem desses alunos.

Uma segunda ação refere-se àqueles alunos que ainda não construíram as estruturas formais. O que fazer para que a integração de novas informações aconteça quando os conhecimentos construídos deixam muito a desejar?

É evidente que os grandes problemas, nesses casos, necessitam ser remediados no início da escolarização, lá na educação infantil e no ensino fundamental, mas se não o são, qual a ação possível da universidade? Infelizmente, e é preciso admitir, esses alunos necessitam percorrer caminhos não percorridos e vivenciar processos típicos de anos anteriores de escolarização. A nosso ver, é por isso que algumas instituições adotam

6 A ABD (Associação Brasileira de Dislexia) conseguiu junto à comissão organizadora do vestibular da FUVEST 2003, alguns benefícios para os disléxicos diagnosticados na própria ABD. Entre eles cumpre destacar: maior tempo para realização da prova, permissão do uso de calculadora, leitura das questões em casos de necessidade e presença de um monitor para anotar a redação do aluno. 
programas de "nivelamento", voltando a matérias e conteúdos básicos do ensino médio e ensino fundamental. Tais programas têm o grande mérito de auxiliar o aluno a reconhecer que houve falhas no processo e que ele pode superá-las, todavia não se deve esquecer que o desenvolvimento cognitivo necessita do avanço das sucessivas reequilibrações do sistema individual e que não basta a transmissão de conteúdos, mas é necessária também a compreensão destes por parte dos alunos.

Portanto, é de fundamental importância avaliar os níveis de conhecimento que possui o aluno adulto. Devemos verificar a existência de organizações internas no indivíduo, que lhe permitam integrar dados e informações cada vez mais complexas. As carências estruturais do conhecimento devem ser identificadas e supridas antes de iniciar o processo de ensino propriamente dito. Os mestres podem encontrar situações específicas de aprendizagem e resoluções de problemas que contribuam para o desenvolvimento dos instrumentos cognitivos mais abstratos, que dêem acesso a capacidades de conceitualização cada vez maiores, tornando assim possível novas aprendizagens. Novamente uma ação psicopedagógica pode auxiliar na reversão do quadro, tanto para um atendimento clínico como num assessoramento institucional.

Há outra questão que também nos parece importante pontuar: muitas vezes nosso aluno do ensino superior já construiu os instrumentos intelectuais do período formal, mas isso não significa que ele irá aplicá-los a todos os conteúdos com os quais se deparar; ou seja, a capacidade do sujeito em raciocinar formalmente não bastaria para que ele aplicasse essa "forma" para outros conteúdos. Isso obviamente acontece com todos nós em muitas situações. Quantos não nos vimos, em relação a matérias e assuntos que não dominamos, termos um raciocínio concreto ou até mais elementar? A esse respeito os professores universitários devem considerar dois aspectos: o do interesse e o dos pontos de ancoragem para a aprendizagem.

O interesse, a motivação, o empenho para a realização de uma tarefa, foram por Piaget definidos como aspectos energéticos e afetivos do desenvolvimento. Para ele, são as necessidades dos sujeitos em vencer os obstáculos que os fazem prosseguir nos processos indissociáveis da assimilação e acomodação, daí vermos a dedicação que ultrapassa horários e limites quando queremos conquistar algo. Portanto, os mestres precisam descobrir as grandes chaves para atingirem o interesse e a motivação dos discentes. Não queremos aqui deixar 


\section{ARTIGO Área Temática: Estudos Piagetianos \& Psicologia Clínica e Educacional}

qualquer ilusão de que deve-se aprender o que se gosta. Aprender é muitas vezes trabalhoso e dolorido. Remetemo-nos todavia à questão afetiva do desequilíbrio, que permite ao sujeito experimentar a dificuldade de assimilar e organizar o conhecimento como fonte de estímulo.

Nesses aspectos, cabe aos professores não somente preocuparem-se com os instrumentos cognitivos que favoreçam a conquista do novo equilíbrio, mas sim intervir num plano mais afetivo na intenção de facilitar a tolerância ao desequilíbrio, ajudando o aprendiz a geri-la eficazmente. O papel do professor passa a ser o de auxiliar para que o aluno não negue simplesmente os desequilíbrios, mas incorpore-os no seu sistema e tente resolvê-los, recorrendo aos seus mecanismos, tornando-os ao mesmo tempo, mais capazes.

A respeito dos pontos de ancoragem, que a nosso ver têm grande relação com a questão afetiva do equilíbrio, devemos considerar que o aluno já tem uma experiência de vida e acontecimentos relacionados ao trabalho, à escola e à afetividade de cada um. Tais aspectos são molas propulsoras para continuação do desenvolvimento e servem como "portos seguros" que permitem dar um sentido aos novos dados e podem ajudar nas novas reflexões. Nas palavras de Legendre (1998):

O reconhecimento destas representações prévias e do seu papel fundamental na aquisição de novos conhecimentos, sugere que um processo de formação não poderia privar-se dos saberes já existentes, uma vez que eles constituem a matériaprima com base na qual se constrói todo o novo saber. Por conseguinte, formar ou ensinar não consiste simplesmente em transmitir um certo número de saberes julgados essenciais, mas em intervir sobre as representações iniciais e as transformar. (LEGENDRE, 1998, p. 159).

Nesse sentido, aprender não pode reduzir-se a um simples adicionar de informações e/ou substituição de representações, pois é necessário uma transformação conceitual., mudando a organização cognitiva. Portanto, na educação superior, assim como em outros níveis de ensino, não podemos esquecer que a experiência nova será assimilada ao sistema de significação do aluno e que a aprendizagem significativa torna-se essencial quando se busca a real compreensão e não simples memorização ou reprodução:

... os processos de crescimento dos conhecimentos ou de transformação do adulto, produzidos por aprendizagens significantes e realizados em relação com acontecimentos ligados às dimensões do trabalho ou da afectividade, constituiriam a relação essencial entre a aprendizagem e o desenvolvimento. (MERRIAM e CLARK apud DANIS, 1998, p.37). 
Situações de aprendizagem significativas podem partir de reflexões sobre 0 papel social do aluno e do profissional e da profissão que ele exercerá, bem como da valorização dos sentimentos e das dificuldades encontradas no processo de formação, da análise de questões éticas envolvendo o trabalho entre muitas outras situações que os mestres podem e devem criar.

\section{CONSIDERAÇÕES FINAIS}

Pretendemos nesse capítulo chamar a atenção para questões teóricas e práticas relacionadas às dificuldades de aprendizagem de estudantes universitários. As pesquisas nesse campo mostram que a terminologia e o conceito de dificuldades de aprendizagem sofreu influências de várias áreas de conhecimento o que acabou, muitas vezes, por dificultar uma unanimidade ou unificação na definição.

Todavia, apesar dos estudos evidenciarem diferentes enfoques para o tema, percebemos que a grande questão que deve ser considerada pelos educadores é se as dificuldades dos seus alunos podem, e até que ponto, ser remediadas e quais as formas de intervenção que os docentes devem utilizar. Esse é o grande mérito da perspectiva construtivista que não coloca somente nos sujeitos a responsabilidade do fracasso, mas analisa as possibilidades de interação desses sujeitos e as responsabilidades do meio, que abre ou fecha tais possibilidades. Isso, sem dúvida, evidencia o papel do professor e da escola quando os alunos apresentam dificuldades.

O aluno do ensino superior necessita de um raciocínio formal para assimilar as novas imposições que a vida universitária lhe coloca. Pensar sobre o próprio pensamento, analisar a sociedade e estabelecer relações entre o que existe e pode existir (raciocínio hipotético dedutivo), trabalhar com conceitos abstratos, refletir e organizar formas para a execução do trabalho, enfim, são muitas atividades que requerem do estudante um pensamento mais destacado do concreto.

Vimos que há várias possíveis explicações para os alunos que não aprendem e que diferentes formas de atuação podem ser pensadas. Nesse ponto salientamos que há poucas pesquisas no âmbito do período operatório formal, normalmente se encontram na passagem 
do período concreto para o formal, mas não enfatizam a equilibração do período formal e nem os estudos com populações adultas (andragogia ${ }^{7}$ ). Esse campo necessita de pesquisas sobretudo aquelas que não apenas diagnostiquem, mas apresentem propostas de intervenção com população de estudantes universitários.

Nesse sentido, um outro campo de pesquisa que se abre também é o da Psicopedagogia voltada para o ensino superior. O trabalho psicopedagógico torna-se bastante importante do ponto de vista do atendimento e orientação para o aluno e do assessoramento aos professores e coordenadores. Há muita pesquisa e muitos dados para serem obtidos aqui.

Vale ressaltar novamente, como dissemos no início, que a democratização do ensino perpassa não somente pela garantia do acesso, mas também pela garantia da permanência. Se o aluno "arrasta-se" pelos anos universitários sem compreender e usufruir do que os estudos podem lhe proporcionar, não há democratização, pois a permanência nesses casos não é com qualidade. Soma-se o fato que muitos alunos acabam desistindo de terminar o curso e evadem. Como será que esses alunos se sentem? Quais a conseqüências disso para sua formação pessoal e profissional? Pesquisas recentes mostram que alunos com dificuldades de aprendizagem sofrem rejeição dos seus pares tanto para aspectos cognitivos como para afetivos (SARAVALI, 2003). Nesse sentido, não basta apenas estar no ensino superior, mas também estar incluído em todas as dimensões que envolvem essa etapa de ensino.

A universidade não cumpre seu papel social quando não inclui todos e perpetua a segregação que começa muitas vezes nos primórdios da escolarização. Diante de um quadro desses como podemos exigir que estes alunos sejam bons profissionais? Mesmo quando as instituições dirigem seus objetivos para a adequação e preparo do aluno para o mercado de trabalho, não devem esquecer que este profissional necessita ser criativo, saber tomar decisões em situações complexas, liderar grupos, otimizar recursos, ter espírito de equipe entre outras características (SARAVALI, 2004). Portanto, para uma formação integral não basta apenas pensar em conteúdos.

\footnotetext{
${ }^{7}$ Segundo Knowles andragogia é "a arte e a ciência de ajudar os adultos a aprender" (apud García, 1999, p.55).
} 
Há uma outra questão também que devemos considerar, não são somente os alunos que têm dificuldades de aprendizagem que podem fracassar, mas aqueles que são provenientes de um modelo de ensino alienante e passivo também podem tornar-se mero reprodutores dos conhecimentos transmitidos (PACHANE, 2001). Esses alunos podem não exercitar o raciocínio formal no sentido da reflexão abstrata que abre novas e cada vez maiores possibilidades de adaptação. Assumindo um caráter passivo, o aluno pode aprender a decorar, copiar, mas não a criar e transformar, o que contribui pouco para favorecer o seu crescimento e a sua formação. Sobre isso Lengendre nos diz:

\begin{abstract}
... um ensino demasiado exclusivamente centrado na memorização e na reprodução fiel daquilo que é ensinado, não favoreceria de todo o desenvolvimento dos instrumentos de abstracção próprios do pensamento formal. Com efeito, na medida em que o pensamento se desenvolve precisamente através da sua utilização, fonte de desequilíbrios e de reequilibrações, um modo de aprendizagem passivo que não solicitasse a actividade do sujeito, não favoreceria de todo a elaboração de novos instrumentos cognitivos. (1998, p.191)
\end{abstract}

Nesse sentido, salientemos que quando o aluno já atingiu o período formal e vem exercitando seus instrumentos intelectuais conforme essa forma de raciocínio exige, mesmo que a interação com o meio diminua, o próprio sistema pode gerar desequilíbrios, colocando e recolocando problemas e desafios para esse sujeito . Isso envolve o pensar sobre o pensar, e é o que deveríamos pretender para nossos alunos do ensino superior, o controle e domínio sobre a própria aprendizagem e a busca constante pelos novos e melhores equilíbrios.

A esse respeito é importante observarmos os cinco princípios que Knowles (apud García, 1999) propôs para a andragogia, relacionando-os com questões pontuadas anteriormente:

1) O autoconceito do adulto, como pessoa madura, evolui de uma situação de dependência para a autonomia - isso é necessário e pode ocorrer quando as situações que favorecem o caminhar para a autonomia são incentivadas e solicitadas, gerando o domínio sobre questões morais e intelectuais. A aprendizagem autônoma inclui aspectos como tomar a iniciativa, planejar, desenvolver e avaliar as próprias atividades de aprendizagem, assim como a capacidade de autogestão e de aprender com a própria experiência; 
2) $\mathrm{O}$ adulto acumula uma ampla variedade de experiências que podem ser um recurso muito rico para a aprendizagem - tal como vimos anteriormente os pontos de ancoragem são importantes para a simbolização, compreensão e aprendizagem dos adultos;

3) A disposição de um adulto para aprender está intimamente relacionada com a evolução das tarefas que representam o seu papel social - portanto, é importante estabelecer os pontos de ancoragem e criar as possibilidades de reflexão a partir das necessidades profissionais e sociais que os novos papéis que esse aluno vai exercer solicitam;

4) Produz-se uma mudança em função do tempo à medida que os adultos evoluem de aplicações futuras do conhecimento para aplicações imediatas - isso relaciona-se diretamente com as situações didáticas que devem ser criadas pelos professores a fim de que estes auxiliem os alunos a pensarem sobre problemas e não somente a aprender conteúdos;

5) Os adultos são motivados para aprender por fatores internos - como vimos anteriormente, não se pode desconsiderar a questão afetiva dos desequilíbrios, embora a nosso ver, haja também, em muitos casos, a presença de motivações extrínsecas, como por exemplo a obtenção do diploma que permite um aumento salarial.

Encerramos salientando que atualmente vemos grande ênfase em estudos sobre técnicas e procedimentos pedagógicos voltados para uma melhor atuação docente. A nosso ver, estes instrumentos são interessantes na medida em que se relacionam com o que tratamos neste capítulo tornando-se meios e não fins. Não seria útil buscar dicas e instruções sobre o fazer docente sem antes se considerar o pensamento do discente. Assim, os mestres precisam conhecer como seus alunos aprendem, como assimilam as informações a fim de poderem, a partir desse conhecimento, direcionar sua prática pedagógica.

\section{REFERÊNCIAS}

BRENELLI, R. P. O jogo como espaço para pensar. Campinas: Papirus, 1996. 208p.

CRUICKSHANK, W.; JOHNSON, G. A educação da criança e do jovem excepcional. Porto Alegre: Globo, 1975. 
CRUZ, V. Dificuldades de aprendizagem - fundamentos. Lisboa: Porto Editora, 1999.

DANIS, C.; SOLAR, C. (org.) Aprendizagem e desenvolvimento dos adultos. Lisboa: Horizontes Pedagógicos, 1998. 301p.

DOLLE, J.; BELLANO, D. Essas crianças que não aprendem - diagnósticos e terapias cognitivas. Tradução: Cláudio Saltini e Lia Leme Zaia. Petropólis: Vozes, 1996. 195p. Título original: Ces enfants Qui n’apprennent pas: diagnostic et remédiations.

FONSECA, V. Introdução às Dificuldades de Aprendizagem. $2^{\mathrm{a}}$ ed. rev. e aum. Porto Alegre: Artes Médicas, 1995. 388p.

FROSTIG, M.; MASLOW, P. Learning problems in the classroom. New York: Grune e Stratton, 1973. 353p.

GARCÍA, C. Formação de professores - para uma mudança educativa. Porto: Porto Editora, 1999.

HARING, N.; BATEMAN, B. Teaching the learning disabled child. Englewood Cliffs, N.J.: Prentice-Hall, 1977. 343p.

INHELDER, B.; PIAGET, J. Da lógica da criança à lógica do adolescente - ensaio sobre a construção das estruturas operatórias formais. Tradução: Dante Moreira Leite. São Paulo: Pioneira, 1976. 260p.

JOHNSON, D.; MYKLEBUST, H. Distúrbios de aprendizagem - princípios e práticas educacionais. $2^{a}$ edição. Tradução: Marília Sanvicente. São Paulo: Pioneira, 1987. 400p. Título Original: Learning Disabilities - educational principles and practices.

KEPHART, N. O aluno de aprendizagem lenta. Tradução: Ieda Sehm. Porto Alegre: Artes Médicas, 1990.

KIRK, S. Educação da criança excepcional. Tradução: Marília Sanvicente. São Paulo: Martins Fontes, 1991.

LEGENDRE, M. Contribuição do modelo da equilibração para o estudo da aprendizagem no adulto. IN: DANIS, C.; SOLAR, C. (Org.) Aprendizagem e desenvolvimento dos adultos. Lisboa: Horizontes Pedagógicos, 1998. p.155-216.

MANTOVANI DE ASSIS, O. Z. A Solicitação do Meio e a construção das estruturas lógicas-elementares pela criança. 1976. Tese (Doutorado em Psicologia Educacional) Faculdade de Educação, Universidade Estadual de Campinas, Campinas.

PACHANE, G. O caráter híbrido da "língua portuguesa" no ensino superior. In: Anais XIII COLE: Congresso de Leitura no Brasil. UNICAMP, 2001. 
RAMOZZI-CHIAROTTINO, Z. Em busca do sentido da obra de Jean Piaget. $2^{\text {a }}$ ed. São Paulo: Ática, 1994. 118p.

ROSS, A. Aspectos psicologicos dos disturbios da aprendizagem e dificuldades na leitura. Tradução: Alexandra Fares. São Paulo: Mc Graw-Hill do Brasil, 1979.

SARAVALI, E.G. Dificuldades de Aprendizagem e Interação Social. 2003. 157f. Tese (Doutorado em Psicologia Educacional) Faculdade de Educação, Universidade Estadual de Campinas, Campinas, 2003.

As relações psicossociais no ensino superior: considerações sobre a formação integral do aluno universitário. 2004 (mimeo).

SISTO, F. Dificuldades de Aprendizagem. In: SISTO, F. et al. Dificuldades de Aprendizagem no contexto psicopedagógico. 2a edição. Petrópolis: Vozes, 2001. p. 19-39.

SMITH, C.; STRICK, L. Dificuldades de Aprendizagem de A a $Z$ - um guia completo para pais e educadores. Tradução: Dayse Batista. Porto Alegre: Artmed, 2001. 332p. Título original: Learning Disabilities: A to Z - a parent's complete guide to learning disabilities from preschool to adulthood.

STRAUSS, A. et al. Psicopatología y educación del niño com lesión cerebral. EUDEBA: Buenos Aires, 1973. 311p.

VELLUTINO, F.R. Alternative conceptualization of dyslexia: evidence in support of a verbal deficit hypothesis. Havard Educational Review, nº 47, 1997.

WOOLFOLK, A. E. Psicologia da Educação. $7^{a}$ edição. Tradução: Maria Cristina Monteiro. Porto Alegre, Artmed, 2000. 568p.

ZAIA, L. L. A solicitação de meio e a construção das estruturas operatórias em crianças com dificuldades de aprendizagem. 1996. 255f. Tese (Doutorado em Psicologia Educacional) Faculdade de Educação, Universidade Estadual de Campinas, Campinas, 1996. 
